\title{
The impact of prior performance on the risk-taking of mutual fund managers
}

\author{
Manuel Ammann • Michael Verhofen
}

Received: 25 May 2006 / Accepted: 12 December 2007 / Published online: 15 February 2008

(C) Springer-Verlag 2008

\begin{abstract}
We analyze the impact of prior performance on the risk-taking behavior of mutual fund managers. We contribute to the existing literature by using different measures of risks, a larger data set, and an econometric approach capturing non-linear effects and assigning exact probabilities to the mutual fund managers' adjustment of behavior. We find that prior performance in the first half of the year has, in general, a positive impact on the choice of the risk level in the second half of the year. Successful fund managers increase the volatility, the beta, and assign a higher proportion of their portfolio to value stocks, small firms, and momentum stocks in comparison to unsuccessful fund managers. Unsuccessful fund manager increase, on average, only the tracking error.
\end{abstract}

Keywords Mutual funds $\cdot$ Risk taking

JEL Classification $\mathrm{G} 11 \cdot \mathrm{G} 20$

\section{Introduction}

The behavior of mutual fund managers has been subject to considerable academic research (e.g. Brown et al. 1996; Chevalier and Ellison 1997; Carpenter 2000). As

We thank an anonymous referee, Bernd Brommundt, Alexander Ising, Stephan Kessler, Axel Kind, Angelika Noll, Jennifer Noll, Ralf Seiz, Stephan Süss, Rico von Wyss, and Andreas Zingg for valuable comments. We acknowledge helpful comments of the participants from the Joint Research Workshop of the University of St. Gallen and the University of Ulm in 2005.

M. Ammann $(\varangle) \cdot$ M. Verhofen

University of St Gallen, St. Gallen, Switzerland

e-mail: manuel.ammann@unisg.ch

M. Verhofen

e-mail: michael.verhofen@unisg.ch; verhofen@gmail.com 
rational agents, mutual fund managers are supposed to adjust their behavior according to the incentives they face. We analyze the impact of prior performance on the risktaking behavior of mutual fund managers and contribute to the existing literature by using different measures of risks, a larger data set, and an econometric approach capturing non-linear effects and assigning exact probabilities to the mutual fund managers' adjustment of behavior. We find that prior performance in the first half of the year has, in general, a positive impact on the choice of the risk level in the second half of the year.

Investors assign new capital primarily to mutual funds that have shown a high return in the previous period, but do not withdraw capital from poor-performing funds to the same extent. This behavior induces a convex relation between net flows and prior performance. If compensation is linked to fund size, this provides an incentive for increasing the riskiness of a portfolio to a suboptimal point from an investor's perspective. Therefore, fund managers might shift the fund's risk in response to the fund's relative performance.

Several authors have analyzed the actual behavior of mutual fund managers empirically. Deli (2002) investigates marginal compensation rates in mutual fund advisory contracts. He finds that marginal compensation depends positively on turnover and the fund type (e.g. equity, closed-end), and is negatively related to fund size and size of the fund family. Therefore, incentives to take risk might differ across fund managers.

Chevalier and Ellison (1997) estimate the shape of the relationship between performance and new fund flows because the shape of this relation creates incentives for fund managers to increase or decrease the riskiness of the fund. They find that funds tend to change their volatility depending on the relative performance by the end of September. Similarly, Brown et al. (1996) focus on mid-year effects. In particular, they test the hypothesis that mutual fund managers showing an underperformance by mid-year change the fund's risk differently than those mutual fund managers showing an outperformance at the same point in time. They find that mid-year losers tend to increase the fund's volatility to a greater extent than their successful counterparts. Busse (2001) suggests that some prior findings might be spurious. Using daily data and the methodology by Brown et al. (1996) he finds no mid-year effect. In sum, existing empirical analyses have failed to deliver clear evidence on the behavior of mutual fund managers and there are doubts about the robustness of the findings.

In this paper, we contribute to the existing empirical literature in a number of ways. In contrast to existing studies, we do not solely focus on volatility as a measure of risk. We also take into account other measures such as the beta, the tracking error, and style measures such as the high-minus-low (HML) factor, the small-minus-big (SMB) factor, and the momentum (UMD) factor. Furthermore, in contrast to previous studies, we use a robust, non-parametric approach. As we do not impose any distributional assumptions, we are able to capture a wide range of non-linear and asymmetric patterns. Moreover, instead of using a particular theoretical model describing the behavior of fund managers as a starting point, our study is designed in an explorative way. Concerning the data, we do not use only a sub-group of mutual funds, but a complete, survival-bias free set of all US equity funds. In contrast to Ammann and Verhofen (2007), this paper focuses on effects within a year and not between different years. 
We compute conditional transition matrices and compare whether the conditional transition matrices are different for successful and unsuccessful mutual funds. We find that prior performance in the first half of the year has, in general, a positive impact on the choice of the risk level in the second half of the year. Successful fund managers increase the volatility, the beta, and assign a higher proportion of their portfolio to value stocks, small firms, and momentum stocks in comparison to unsuccessful fund managers. Unsuccessful fund manager increase, on average, only the tracking error.

Section 2 starts by presenting the research design approach. Section 3 presents the empirical results. Section 4 concludes.

\section{Methodology}

In this section, we describe the approach to analyze the change in behavior. The approach can be summarized as follows. First, we estimate different measures of risk and return for the first and second half of each year. Then, we assign each fund to a class depending on the estimated factor loading. Third, we compute the transition probabilities for each fund depending on its past performance.

\subsection{Data}

For the analysis, we use a complete, survivial-bias free sample of all US funds as starting point. The data are from CRSP and have a daily frequency. The sample starts in January 2001 and ends in December 2005. In our analysis, we use all funds with a S\&P style rating in the categories all caps ( $\mathrm{S} \& \mathrm{P}$ style codes $\mathrm{ACG}$ and $\mathrm{ACV}$ ), large caps (LCB, LCG, LCV), medium caps (MCB, MCG, MCV), and small caps (MCB, MCG, MCV). The data for the risk premia (market risk premium, size premium, value premium, momentum premium, risk-free rate) are from the website of Fama and French.

The sample period is with a length of 5 years relatively short. This is, of course, a limitation, but it is triggered by the data available in CRSP. Data with a monthly frequency are available for a longer time period, but for daily data the sample starts in 2001. A reliable estimate of a four factor model cannot be done with monthly data because only six data points (for each half of the year) would be available. However, our sample contains panel data of about 8.000 different funds. The large number of cross-sectional fund data reduces therefore the disadvantage of the short sample period.

\subsection{Style regressions}

To measure a fund's performance, a number of different approaches have been suggested (e.g. Kothari and Warner 2001; Wermers 2000; Daniel et al. 1997). To estimate the exposure to the Fama and French (1993) risk factors and the Carhart (1997) momentum factor, we run the following regression for each fund $i$

$$
\begin{aligned}
r_{i}-r_{f}= & \alpha_{i, t}+\beta_{M R P, i, t} \cdot M R P_{\text {Carhart }, i, t}+\beta_{H M L, i, t} \cdot H M L_{i, t} \\
& +\beta_{S M B, i, t} \cdot S M B_{i, t}+\beta_{U M D, i, t} \cdot U M D_{i, t}+\varepsilon_{i, t}
\end{aligned}
$$


where $r_{i, t}$ denotes the return of a fund $i, r_{f}$ the risk-free rate, $\varepsilon_{\text {Carhart }, i, t}$ the regression residual, and $t$ is the time index. The coefficients to be estimated are denoted by $\beta_{M R P, i, t}, \beta_{H M L, i, t}, \beta_{S M B, i, t}, \beta_{U M D, i, t}$ and the risk premia by $M R P_{i, t}, H M L_{i, t}$, $S M B_{i, t}$, and $U M D_{i, t}$. We run the regressions on a half-year basis.

The tracking error measures a fund's deviation from a passive index. We define the tracking error $T E$ as the volatility $\sigma$ of the residuals of the regressions on the index, i.e.,

$$
T E_{i, t}=\sigma\left(\varepsilon_{i, t}\right)
$$

\subsection{Estimation of transition matrices}

In this paper, we compute unconditional and conditional transition matrices and compare whether the conditional transition matrices are different for successful and unsuccessful mutual funds. The approach we are using to compute transition matrices is widely used in credit risk and is, for example, described in Höse et al. (2002).

We group all estimated factor loadings in $d$ categories ranging from 1 , the lowest factor loading, to the category $d$ containing the highest factor loadings. The $n$ observed migration events form a $n \times 2$ matrix with rows

$$
\left(e_{i 1}, e_{i 2}\right) \in\{1, \ldots, d\} \times\{1, \ldots, d\}, \quad i=1, \ldots, n .
$$

Thereby, $e_{i 1}$ characterizes the factor loading of the $i$ th fund at the beginning and $e_{i 2}$ the factor loading at the end of the observation period. Subsequently, migration events of the same kind are aggregated in a $d \times d$ matrix $\mathbf{C}$ of migration frequencies where the generic element

$$
c_{j k}=\sum_{i=1}^{n} 1\left\{\left(e_{i 1}, e_{i 2}\right)=(j, k)\right\}
$$

is the number of migration events from $j$ to $k$. We assume that each observation $e_{i 2}$ is a realization of a random variables $\tilde{e}_{i 2}$ with conditional probability distribution

$$
p_{j k}=\mathrm{P}\left(\tilde{e}_{i 2}=k \mid \tilde{e}_{i 1}=j\right), \quad \sum_{k=1}^{d} p_{j k}=1
$$

where $p_{j k}$ is the probability of a fund migrating from an initial factor loading $j$ to $k$. In order to estimate these transition probabilities we define the number of migrations starting from class $j$ as

$$
n_{j}=\sum_{k=1}^{d} c_{j k}, \quad j=1, \ldots, d
$$


The observed migration rate from $j$ to $k$

$$
\hat{p}_{j k}=\frac{c_{j k}}{n_{j}}
$$

is the estimate of the unknown transition probability (Höse et al. 2002). The standard deviation of $\hat{p}_{j k}$ is

$$
\hat{\sigma}_{j k}=\sqrt{\frac{\hat{p}_{j k}\left(1-\hat{p}_{j k}\right)}{n_{j}}}
$$

if the variables $e_{i 1}, e_{i 2}$ are stochastistically independent.

In the empirical part, we set $d=5$. Therefore, we obtain $5 \times 5$ transition matrices. We refer to the categories as quintile $1(\mathrm{Q} 1)$, quintile $2(\mathrm{Q} 2)$, quintile $3(\mathrm{Q} 5)$, quintile 4(Q4), and quintile 5 (Q5). We set $d=5$ because similar classifications are used in papers analyzing the performance of asset pricing models (e.g., Fama and French 1992).

\subsection{Statistical inference}

In this section, we show how different transition matrices can be compared from a statistical point of view.

The null hypothesis of homogeneity, i.e., that two transition matrices are equal, can be tested (Höse et al. 2002) with a chi-squared test. The test statistic

$$
\chi^{2}=\sum_{k=1}^{d} \sum_{s=1}^{m} \frac{\left[c_{j k}(s)-n_{j}(s) \hat{p}_{j k}^{+}\right]^{2}}{n_{j}(s) \hat{p}_{j k}^{+}}
$$

is distributed $\chi^{2}$ with $(d-1)(m-1)$ degrees of freedom. $\hat{p}_{j k}^{+}$is the estimated transition probability based on the pooled data. and $s$ it the index for the respective sample (e.g., top-performing funds and poor-performing funds). In our setting, $m=2$ because we compare two transition matrices.

\section{Empirical results}

The analysis is structured as follows. After presenting some descriptive statistics, we first analyze the impact of prior performance on the risk-taking in the mean-variance model. Then, we turn to the Carhart (1997) four-factor model and analyze the impact for the loading on the market risk factor, the size premium, the value premium, the momentum premium, and the tracking error. Finally, we analyze the stability of our findings for sub-samples.

\subsection{Breakpoints}

Table 1 shows the median return and the median volatility for each quintile. We observe a number of interesting patterns for different portfolios and during time. Returns and 
Table 1 Median return and volatility

\begin{tabular}{|c|c|c|c|c|c|c|c|c|c|c|}
\hline \multirow[t]{2}{*}{ Time period } & \multicolumn{5}{|l|}{ Return } & \multicolumn{5}{|c|}{ Volatility } \\
\hline & Q1 & Q2 & Q3 & Q4 & Q5 & Q1 & Q2 & Q3 & Q4 & Q5 \\
\hline 2001-1 & -11.12 & -4.69 & -1.27 & 4.27 & 12.65 & 1.00 & 1.22 & 1.43 & 1.73 & 2.29 \\
\hline $2001-2$ & -11.75 & -6.81 & -4.76 & -2.49 & 2.07 & 1.01 & 1.18 & 1.27 & 1.42 & 1.74 \\
\hline $2002-1$ & -23.01 & -16.31 & -12.21 & -6.87 & 0.92 & 0.86 & 1.01 & 1.13 & 1.22 & 1.44 \\
\hline $2002-2$ & -16.72 & -12.86 & -10.60 & -8.94 & -6.30 & 1.62 & 1.81 & 1.92 & 2.00 & 2.19 \\
\hline 2003-1 & 8.92 & 11.06 & 12.34 & 14.44 & 18.65 & 1.03 & 1.16 & 1.24 & 1.30 & 1.39 \\
\hline $2003-2$ & 11.64 & 13.79 & 15.33 & 18.14 & 22.75 & 0.69 & 0.78 & 0.85 & 0.98 & 1.20 \\
\hline 2004-1 & 0.93 & 2.87 & 3.91 & 5.63 & 8.41 & 0.68 & 0.75 & 0.82 & 0.95 & 1.17 \\
\hline 2004-2 & 3.65 & 6.29 & 7.64 & 9.50 & 11.80 & 0.61 & 0.67 & 0.75 & 0.87 & 1.04 \\
\hline $2005-1$ & -3.33 & -1.09 & 0.09 & 1.40 & 3.58 & 0.62 & 0.68 & 0.73 & 0.82 & 0.97 \\
\hline $2005-2$ & 3.55 & 5.55 & 6.68 & 8.20 & 10.93 & 0.58 & 0.63 & 0.69 & 0.80 & 0.95 \\
\hline
\end{tabular}

The table shows the median return and volatility for each quintile for the first and second half of each year in the sample period. Return is the total return in percent over the relevant time period and volatility the daily volatility in percent

volatilities reflect the general stock market development during the sample period. In 2001 and 2002 most funds had negative returns and higher volatilities than in the period 2003-2005.

In the cross-section of the portfolios, we find that the dispersion of returns was greatly reduced during the sample period. For example, the median return in 2001-1 (first half of 2001) was $-11.12 \%$ in Q1 and $12.65 \%$ in Q5. This sums to a dispersion of approximately $23 \%$ between the highest and lowest quintile. In contrast, the median return in 2005-1 was $-3.33 \%$ in quintile 1 and $3.58 \%$ in quintile 5 . The dispersion reduced to $7 \%$ between the highest and lowest quintile. A similar pattern can be observed for volatility. For example, in the first half of 2001, the median volatility was $1.00 \%$ per day in Q1 and 2.29\% per day in Q5. In contrast, in the first half of 2005, the median volatility was $0.62 \%$ per day in Q1 and $0.97 \%$ per day in Q5.

Table 2 shows the median alpha, tracking error (TE), and the factor loadings on the market risk premium (MRP), size premium (SMB), value premium (HML), and momentum premium (UMD) for each quintile for the first and second half of each year in the sample period.

For the alpha, we find that the dispersion of alphas has declined over time. In the first half of 2001, the median alpha was -0.07 in quintile 1 and 0.06 in quintile 5. In the second half of 2005, the median alpha was -0.01 in quintile 1 and 0.04 in quintile 5. The dispersion of $0.13(0.06-(-0.07))$ in 2001 has reduced to a value of $0.05(0.04$ $-(-0.01))$ in 2005. One possible explanation for this finding is that capital markets became more efficient and therefore harder to generate excess returns relative to the Carhart (1997) four-factor model.

For the loading on the market risk premium, we find a high degree of stability over time in each quintile. For example, the beta of quintile 3 is close to 1 at each point in time. The highest quintile shows a slight downward trend from 1.23 in 2001-1 to 1.09 
Table 2 Median factor loadings

\begin{tabular}{|c|c|c|c|c|c|c|c|c|c|c|c|c|c|c|}
\hline \multirow[t]{2}{*}{ Time period } & \multicolumn{4}{|l|}{ Alpha } & \multicolumn{5}{|l|}{ MRP } & \multicolumn{5}{|l|}{ SMB } \\
\hline & Q1 & Q3 & Q4 & Q5 & Q1 & $\mathrm{Q} 2$ & Q3 & Q4 & Q5 & Q1 & Q2 & Q3 & Q4 & Q5 \\
\hline 2001-1 & $-0.07-0.02$ & 0.01 & 0.03 & 0.06 & 0.84 & 0.95 & 1.02 & 1.11 & 1.23 & -0.22 & -0.07 & 0.09 & 0.44 & 0.87 \\
\hline $2001-2$ & $-0.04-0.01$ & 0.01 & 0.02 & 0.04 & 0.83 & 0.94 & 1.00 & 1.05 & 1.13 & -0.16 & -0.06 & 0.08 & 0.36 & 0.75 \\
\hline $2002-1$ & $-0.08-0.03-$ & -0.01 & 0.01 & 0.03 & 0.84 & 0.96 & 1.02 & 1.07 & 1.20 & -0.18 & -0.10 & 0.04 & 0.35 & 0.77 \\
\hline $2002-2$ & $-0.05-0.02-$ & -0.01 & 0.00 & 0.03 & 0.86 & 0.97 & 1.01 & 1.05 & 1.11 & -0.16 & -0.08 & 0.06 & 0.32 & 0.73 \\
\hline 2003-1 & $-0.05-0.03-$ & $-0.01-$ & -0.00 & 0.01 & 0.89 & 0.98 & 1.02 & 1.06 & 1.12 & -0.17 & -0.08 & 0.05 & 0.37 & 0.82 \\
\hline $2003-2$ & $-0.04-0.02-$ & $-0.01-$ & -0.00 & 0.02 & 0.82 & 0.93 & 1.01 & 1.07 & 1.14 & -0.16 & -0.09 & 0.03 & 0.30 & 0.77 \\
\hline 2004-1 & $-0.02-0.01$ & 0.00 & 0.01 & 0.03 & 0.86 & 0.94 & 0.99 & 1.03 & 1.07 & -0.19 & -0.11 & 0.01 & 0.25 & 0.73 \\
\hline 2004-2 & $-0.02-0.01-$ & -0.00 & 0.01 & 0.03 & 0.87 & 0.97 & 1.01 & 1.05 & 1.09 & -0.18 & -0.10 & 0.04 & 0.31 & 0.76 \\
\hline $2005-1$ & $-0.01 \quad 0.00$ & 0.01 & 0.02 & 0.03 & 0.86 & 0.96 & 1.01 & 1.05 & 1.10 & -0.20 & -0.11 & 0.03 & 0.34 & 0.81 \\
\hline \multirow[t]{3}{*}{$2005-2$} & $-0.01-0.00$ & 0.01 & 0.02 & 0.04 & 0.85 & 0.94 & 0.99 & 1.04 & 1.09 & -0.18 & -0.09 & 0.03 & 0.31 & 0.76 \\
\hline & \multicolumn{4}{|l|}{ HML } & \multicolumn{5}{|c|}{ UMD } & \multicolumn{5}{|l|}{ TE } \\
\hline & $\mathrm{Q} 2$ & Q3 & Q4 & Q5 & Q1 & $\mathrm{Q} 2$ & Q3 & Q4 & Q5 & Q1 & Q2 & Q3 & Q4 & Q5 \\
\hline 2001-1 & $-0.47-0.08$ & 0.12 & 0.37 & 0.61 & -0.19 & -0.03 & 0.04 & 0.10 & 0.20 & 0.05 & 0.10 & 0.16 & 0.29 & 0.66 \\
\hline $2001-2$ & $-0.28-0.10-$ & -0.00 & 0.12 & 0.33 & -0.28 & -0.06 & 0.04 & 0.11 & 0.23 & 0.03 & 0.07 & 0.11 & 0.19 & 0.38 \\
\hline $2002-1$ & $-0.26-0.06$ & 0.16 & 0.29 & 0.45 & -0.24 & -0.05 & 0.03 & 0.09 & 0.20 & 0.02 & 0.06 & 0.09 & 0.14 & 0.27 \\
\hline $2002-2$ & $-0.37-0.14-$ & -0.01 & 0.16 & 0.36 & -0.21 & -0.04 & 0.02 & 0.07 & 0.17 & 0.04 & 0.08 & 0.13 & 0.20 & 0.36 \\
\hline 2003-1 & $-0.35-0.11$ & 0.05 & 0.24 & 0.42 & -0.18 & -0.05 & 0.00 & 0.04 & 0.12 & 0.02 & 0.04 & 0.06 & 0.10 & 0.18 \\
\hline $2003-2$ & $-0.27-0.07$ & 0.08 & 0.20 & 0.34 & -0.14 & -0.03 & 0.03 & 0.15 & 0.36 & 0.01 & 0.03 & 0.04 & 0.07 & 0.13 \\
\hline 2004-1 & $-0.36-0.13$ & 0.03 & 0.19 & 0.39 & -0.17 & -0.04 & 0.04 & 0.18 & 0.43 & 0.01 & 0.03 & 0.04 & 0.07 & 0.11 \\
\hline 2004-2 & $-0.50-0.24$ & -0.05 & 0.12 & 0.30 & -0.10 & -0.02 & 0.03 & 0.09 & 0.22 & 0.01 & 0.02 & 0.04 & 0.06 & 0.11 \\
\hline $2005-1$ & $-0.41-0.18-$ & -0.05 & 0.11 & 0.29 & -0.14 & -0.03 & 0.03 & 0.11 & 0.26 & 0.01 & 0.02 & 0.03 & 0.06 & 0.10 \\
\hline $2005-2$ & $-0.45-0.18$ & -0.04 & 0.11 & 0.29 & -0.17 & -0.06 & 0.02 & 0.14 & 0.33 & 0.01 & 0.02 & 0.03 & 0.05 & 0.09 \\
\hline
\end{tabular}

The table shows the median alpha, tracking error and the factor loadings on the market risk premium (MRP), size premium (SMB), value premium (HML), and momentum premium (UMD) for each quintile for the first and second half of each year in the sample period

in 2005-2. Funds with a high exposure to market risk have reduced their exposure to market risk in the sample period.

For the loading on the size factor, we find a similar degree of stability in the sample period. Quintiles 1 and 2 have a negative loading on the size premium at any time. Funds in these quntiles therefore focus primarily on large caps in their investment strategy. In contrast, quintiles 3-5 have always a positive loading on the size factor, i.e., they focus on small stocks. We conclude that in our sample strategies focussing on small caps are more popular than strategies focussing on large caps.

Funds with a negative loading on the value factor can be interpreted as growth funds and funds with a positive loading on the value factor can be interpreted as value funds. We find that the popularity of value and growth-based approaches has changed over time. In 2001-1, for example, funds were, in general, in favor of value-based strategies 
indicated by a factor loading of 0.12 for quintile 3. In contrast, in 2005-2 funds were more in favor of growth strategies indicated by a median value of -0.04 for Q3.

For the loading on the momentum premium, we find-similar to the loading on the size premium - a high degree of stability. A negative loading on the momentum factor can be interpreted as a contrarian investment strategy, a positive loading as a trend following strategy. We find that momentum investing is, on average, more popular than contrarian investing. This is indicated by a positive median in quintile 3 at any time. Over time, funds with a high exposure to momentum strategies (Q5) varied their factor loading considerably. Between 2001-1 and 2003-1 it dropped from 0.20 to 0.12, and increased to 0.33 until the end of the sample period.

The tracking error measures the degree of active portfolio management as the volatility of the residuals of a regression of fund returns on the risk factors. In the sample period, the degree of active portfolio management was reduced substantially among all funds in the sample. For example, the median tracking error was 0.05 for quintile 1 and 0.66 for quintile 5 in 2001-1. Five years later, the median tracking error was 0.01 in quintile 1 and 0.09 in quintile 5. Overall, fund managers took much less residual risk in 2005 than in 2001.

\subsection{Volatility}

Table 3 shows the relation between prior performance and volatility. The results in this table are based on a mean-variance model. The first matrix is the unconditional matrix. The second matrix is the transition matrix for top-performing funds, i.e., funds with a return in the highest quintile in the first half of a year. The third matrix is the transition matrix for poor-performing funds, i.e., funds with a return in the lowest quintile in the first half of year. The last matrix is the difference between the transition matrix of top-performing funds and low-performing funds. The column "Mean" indicates the mean target class for each row of the transition matrix. The mean target class for each row is the probability-weighted average of the number of the class after transition. For example, for the first row in Table 3 , it is computed as $65.19 \% \times 1+18.83 \% \times 2+$ $7.98 \% \times 3+5.21 \% \times 4+2.79 \% \times 5=1.62$. It is a measure of the average category after transition. However, this measure should be interpreted carefully. For example, this measure does not capture non-linear behavior. The mean class after transition might be equal for two different groups although in one group the mass of observations is concentrated in the middle and in the other group the mass of the observations are in the high and low classes.

As a measure for a statistically different behavior, we use the probabilities for the $\chi^{2}$-test shown in column " $p$ " and column "P". The $\chi^{2}$-test is described in Section 2.4. The probabilities in column " $p$ " are based on a row-by-row comparison while the probabilities in column " $\mathrm{P}$ " are based on a comparison of two complete transition matrices. Throughout the empirical part, the $\chi^{2}$-test shows that most findings are highly significant. For example, the $\chi^{2}$-test shows that the transition matrices for top and low-performing funds are statistically different on a $1 \%$ level.

The unconditional transition matrix indicates a high degree of persistence in the choice of the volatility level. For example, funds with a volatility in Q1 choose a 
Table 3 Transition probabilities for volatility

\begin{tabular}{|c|c|c|c|c|c|c|c|c|c|}
\hline & & \multicolumn{8}{|c|}{ Volatility July-December } \\
\hline & & Q1 & Q2 & Q3 & Q4 & Q5 & Mean & $\mathrm{p}$ & $\mathrm{P}$ \\
\hline Volatility & Q1 & 65.19 & 18.83 & 7.98 & 5.21 & 2.79 & 1.62 & & \\
\hline \multirow[t]{4}{*}{ January-June } & $\mathrm{Q} 2$ & 22.87 & 43.58 & 20.00 & 7.61 & 5.93 & 2.30 & & \\
\hline & Q3 & 7.78 & 23.21 & 43.47 & 19.90 & 5.65 & 2.92 & & \\
\hline & Q4 & 2.67 & 11.65 & 21.83 & 48.47 & 15.38 & 3.62 & & \\
\hline & Q5 & 1.48 & 2.74 & 6.72 & 18.81 & 70.25 & 4.54 & & \\
\hline Volatility & Q1 & $57.13^{* *}$ & $21.33^{*}$ & $9.86^{*}$ & $7.62^{* *}$ & $4.06^{*}$ & 1.80 & $0.00 * *$ & \\
\hline \multirow[t]{4}{*}{ top funds } & Q2 & $14.39^{* *}$ & $36.67^{* *}$ & $25.16^{* *}$ & $9.70 *$ & $14.07^{* *}$ & 2.72 & $0.00 * *$ & \\
\hline & Q3 & $3.07^{* *}$ & $15.35^{* *}$ & 44.11 & $24.87^{* *}$ & $12.59^{* *}$ & 3.29 & $0.00 * *$ & \\
\hline & Q4 & $0.16^{* *}$ & $2.27^{* *}$ & $13.44^{* *}$ & $61.72^{* *}$ & $22.42^{* *}$ & 4.04 & $0.00 * *$ & \\
\hline & Q5 & $0.60 * *$ & $0.98^{* *}$ & $2.95^{* *}$ & 19.18 & $76.28^{* *}$ & 4.70 & $0.00 * *$ & $0.00^{* *}$ \\
\hline Volatility & Q1 & $70.60^{* *}$ & 17.71 & 7.06 & $3.13^{* *}$ & $1.50^{* *}$ & 1.47 & $0.00 * *$ & \\
\hline \multirow[t]{4}{*}{ bottom funds } & Q2 & $34.04^{* *}$ & $34.99^{* *}$ & $23.78^{*}$ & $4.65^{* *}$ & $2.54^{* *}$ & 2.07 & $0.00 * *$ & \\
\hline & Q3 & $13.35^{* *}$ & $29.87^{* *}$ & $40.26^{*}$ & $14.34^{* *}$ & $2.18^{* *}$ & 2.62 & $0.00 * *$ & \\
\hline & $\mathrm{Q} 4$ & $6.54^{* *}$ & 11.74 & 23.48 & $42.65^{* *}$ & 15.59 & 3.49 & $0.00 * *$ & \\
\hline & Q5 & 1.49 & 2.44 & $4.97^{* *}$ & 18.54 & $72.56^{*}$ & 4.58 & $0.02 *$ & $0.00^{* *}$ \\
\hline Difference & Q1 & $-13.47^{* *}$ & $3.62^{* *}$ & $2.80^{* *}$ & $4.50^{* *}$ & $2.55^{* *}$ & 0.33 & $0.00 * *$ & \\
\hline between top & Q2 & $-19.65^{* *}$ & 1.68 & 1.38 & $5.05^{* *}$ & $11.54^{* *}$ & 0.66 & $0.00 * *$ & \\
\hline \multirow[t]{3}{*}{ and bottom } & Q3 & $-10.28^{* *}$ & $-14.52^{* *}$ & $3.86^{*}$ & $10.53^{* *}$ & $10.41^{* *}$ & 0.66 & $0.00 * *$ & \\
\hline & $\mathrm{Q} 4$ & $-6.38^{* *}$ & $-9.47^{* *}$ & $-10.04^{* *}$ & $19.07^{* *}$ & $6.83^{* *}$ & 0.55 & $0.00 * *$ & \\
\hline & Q5 & $-0.89^{* *}$ & $-1.45^{* *}$ & $-2.02^{* *}$ & 0.65 & $3.72^{* *}$ & 0.11 & $0.01 * *$ & $0.00^{* *}$ \\
\hline
\end{tabular}

The table shows the relation between prior performance and volatility based on the mean-variance model. The first transition matrix is the unconditional transition matrix. The second transition matrix is the transition matrix for top-performing funds, i.e., funds with a return in the highest quantile in the first half of a year. The third transition matrix is the transition matrix for poor-performing funds, i.e., funds with a return in the lowest quantile in the first half of year. The last matrix is the difference between the transition matrix of top-performing funds and low-performing funds. The column "Mean" indicates the mean target category for each row of the transition matrix. The column "p" shows the probabilities that the transition probabilities are equal (row-by-row) and the column "P" shows the probabilities that the transition matrices are equal. For top-performing and poor-performing funds, significance ( $t$ test and $\chi^{2}$-test) is tested against the unconditional transition matrix. For the last matrix, zero is used as null hypothesis

* Significance on a $5 \%$ level and ** on a $1 \%$ level

volatility in Q1 in the second half of the year with a probability of $65.19 \%$. Similarly, funds with a volatility in the highest quintile (Q5) have a likelihood of $70.25 \%$ to remain in this quintile in the second half of the year.

In contrast to the unconditional case, funds with a high return in the first half of the year tend to increase their volatility to a stronger extent than the remaining funds. For example, successful funds in the lowest quintile (Q1) have a probability of $57.13 \%$ to choose a volatility in the lowest quintile in the second have of the year. Compared to the unconditional probability of $65.19 \%$, the difference is approximately $8 \%$. Similarly, the probability for successful funds in the highest quintile (Q5) to remain in this class 
is $76.28 \%$. Compared to the unconditional probability of $70.25 \%$, the difference is approximately $6 \%$. The transition probabilities for successful funds are in general significantly different from the unconditional probabilities.

The mean class for each row gives a rough measure of the magnitude of change in the risk level. For example, the mean class for the first row for the unconditional transition matrix is 1.62 , for successful funds the mean is 1.80 . This indicates that successful funds choose a higher risk level than the average funds. This conclusion is also valid for all other rows because the mean class after transition is always higher for successful funds than for the full sample average. For example, the difference is $0.42(2.72-2.30)$ for class $2,0.37$ (3.29-2.30) for class $3,0.42$ (4.04-3.62) for class 4 , and $0.26(4.70-4.54)$ for class 5 .

For poor-performing funds, we find the opposite pattern, i.e., that unsuccessful funds take less risk in the second half of the year compared to the full sample average. For example, for unsuccessful funds in the lowest quintile (Q1) the probability of remaining in the lowest quintile is $70.60 \%$ compared to $65.19 \%$ for the full sample. The transition probabilities for unsuccessful funds are in general significantly different from the unconditional probabilities.

The mean class for each row reveals that unsuccessful funds take, in general, less risk than the average fund. For example, the mean class after transition for unsuccessful funds in the lowest quintile is 1.47 compared to 1.62 for the full sample average.

The difference of the transition matrices of top and poor-performing funds reveals the substantial change in behavior of these two subgroups. For example, the difference of the probabilities for the transition for quintile 1 to quintile 1 is $-13.47 \%$. Therefore, top-performing funds are $13.47 \%$ more likely to switch to a different risk level than poor-performing funds ( 57.13 vs. $70.60 \%$ ). In this setting, it is helpful to have a closer look at the mean difference in the class after transition. These values are displayed in the last column of Table 3. A positive value means that, on average, successful funds select a higher risk level than unsuccessful funds. For volatility, all values are positive. This means that successful funds choose a higher risk level than unsuccessful funds.

The $\chi^{2}$-tests show that all empirical findings are highly significant on a $1 \%$ level with the exception for one row-by-row comparison. This tests enable us to draw four important conclusions. First, the transition matrix for top performing funds is different from the unconditional transition matrix. Second, the transition matrix for poor-performing funds is different from the unconditional transition matrix. Third, the transition matrix for top and poor-performing funds are different from each other. Fourth, these findings also hold for each single class of the transition matrices.

\subsection{Market risk}

Table 4 shows the relation between prior performance and the exposure to the market risk, i.e., the beta. The results in this table are based on the estimated factor loadings for the Carhart four-factor model.

The unconditional transition matrix shows some degree of stability in the choice of the beta for funds with a very low or very high exposure to market risk, i.e., funds in quintile 1 or quintile 5 . The unconditional probability for funds in Q1 to remain in this 
Table 4 Transition probabilities for the loading on the market risk premium

\begin{tabular}{|c|c|c|c|c|c|c|c|c|c|}
\hline & & \multicolumn{8}{|c|}{ MRP July-December } \\
\hline & & Q1 & Q2 & Q3 & Q4 & Q5 & Mean & $\mathrm{p}$ & $\mathrm{P}$ \\
\hline MRP & Q1 & 57.82 & 20.31 & 9.80 & 6.39 & 5.68 & 1.82 & & \\
\hline \multirow[t]{4}{*}{ January-June } & Q2 & 18.17 & 28.99 & 25.16 & 16.12 & 11.56 & 2.74 & & \\
\hline & Q3 & 9.73 & 21.34 & 27.44 & 27.49 & 14.00 & 3.15 & & \\
\hline & Q4 & 7.87 & 17.46 & 23.14 & 26.82 & 24.71 & 3.43 & & \\
\hline & Q5 & 6.40 & 11.90 & 14.47 & 23.18 & 44.04 & 3.87 & & \\
\hline \multirow{5}{*}{$\begin{array}{l}\text { MRP } \\
\text { top funds }\end{array}$} & Q1 & $54.66^{*}$ & $22.64^{*}$ & 10.33 & 5.97 & 6.39 & 1.87 & $0.04 *$ & \\
\hline & Q2 & 19.55 & 31.34 & $21.18^{* *}$ & 17.22 & 10.71 & 2.68 & $0.01 * *$ & \\
\hline & Q3 & 10.03 & 19.67 & 29.55 & 27.37 & 13.37 & 3.14 & 0.37 & \\
\hline & Q4 & $11.00^{* *}$ & $22.11^{* *}$ & 22.66 & $19.06^{* *}$ & 25.16 & 3.25 & $0.00 * *$ & \\
\hline & Q5 & $8.70^{*}$ & $18.16^{* *}$ & $18.41^{*}$ & 21.74 & $32.99^{* *}$ & 3.52 & $0.00 * *$ & $0.00^{* *}$ \\
\hline \multirow{5}{*}{$\begin{array}{l}\text { MRP } \\
\text { bottom funds }\end{array}$} & Q1 & 60.86 & 19.00 & 8.56 & $8.35^{*}$ & $3.24^{* *}$ & 1.74 & $0.00 * *$ & \\
\hline & Q2 & $21.32^{*}$ & 28.68 & 23.90 & 14.71 & 11.40 & 2.66 & 0.20 & \\
\hline & Q3 & $13.93^{* *}$ & $24.23^{*}$ & $24.01 *$ & $22.70^{* *}$ & 15.13 & 3.01 & $0.00^{* * *}$ & \\
\hline & Q4 & $11.17^{* *}$ & $22.65^{* *}$ & 22.33 & $23.87 *$ & $19.98^{* *}$ & 3.19 & $0.00^{* *}$ & \\
\hline & Q5 & 7.50 & $14.06^{*}$ & 14.36 & $21.16^{*}$ & 42.92 & 3.78 & $0.00 * *$ & $0.00^{* *}$ \\
\hline \multirow{5}{*}{$\begin{array}{l}\text { Difference } \\
\text { between top } \\
\text { and bottom }\end{array}$} & Q1 & $-6.20^{* *}$ & $3.64^{* *}$ & $1.78^{*}$ & $-2.38^{* *}$ & $3.16^{* *}$ & 0.13 & $0.05^{*}$ & \\
\hline & Q2 & -1.77 & $2.67^{*}$ & $-2.72^{*}$ & $2.52^{*}$ & -0.69 & 0.02 & 0.69 & \\
\hline & Q3 & $-3.89^{* *}$ & $-4.56^{* *}$ & $5.54^{* *}$ & $4.67^{* *}$ & -1.76 & 0.14 & $0.04 *$ & \\
\hline & Q4 & -0.16 & -0.54 & 0.33 & $-4.80^{* *}$ & $5.18^{* *}$ & 0.06 & 0.14 & \\
\hline & Q5 & 1.20 & $4.10^{*}$ & $4.06^{*}$ & 0.57 & $-9.93^{* *}$ & -0.26 & $0.00 * *$ & $0.00^{* *}$ \\
\hline
\end{tabular}

The table shows the relation between prior performance and the loading on the market risk premium based on the four-factor model. The first transition matrix is the unconditional transition matrix. The second transition matrix is the transition matrix for top-performing funds, i.e., funds with an alpha in the highest quantile in the first half of a year. The third transition matrix is the transition matrix for poor-performing funds, i.e., funds with an alpha in the lowest quantile in the first half of year. The last matrix is the difference between the transition matrix of top-performing funds and low-performing funds. The column "Mean" indicates the mean target category for each row of the transition matrix. The column " $p$ " shows the probabilities that the transition probabilities are equal (row-by-row) and the column "P" shows the probabilities that the transition matrices are equal. For top-performing and poor-performing funds, significance ( $t$ test and $\chi^{2}$-test) is tested against the unconditional transition matrix. For the last matrix, zero is used as null hypothesis

* Significance on a $5 \%$ level and $* *$ on a $1 \%$ level

quintile in the second half of the year is $57.82 \%$, for funds in quintile 5, 44.04\%. For the quintiles 2-4, the probabilities are with values between $26.82 \%$ (Q4) and 28.99 (Q2) much lower. These funds are therefore more likely to change their risk level.

Overall, the transition for successful funds in the first half of the year is very similar to the unconditional transition matrix although some probabilities are significantly different. For example, a mean class after transition of 1.87 for quintile 1 for successful funds compared to 1.82 for all funds indicates a small tendency to increase risk. For the remaining quintiles, we find the mean class for successful funds is below the mean class for all funds. This can be interpreted as an indication for decreased risk-taking for successful funds. 
The transition matrix for unsuccessful funds is very similar to the unconditional transition matrix. Some probabilities are significantly different while others are not. For all classes, the mean class after transition for unsuccessful funds is below the unconditional transition matrix. This indicates that unsuccessful funds take less risk than the average fund.

The patterns for successful and unsuccessful funds are very similar to each other. A comparison of the transition matrices based on the mean class after transition for these subcategories reveals that successful funds are more likely to increase their risk level. This finding holds, in general, for quintiles 1-4. For the fifth quintile, we find that successful funds tend to decrease their exposure to the market risk factor.

The $\chi^{2}$-tests show that all transition matrices are different from each offer on a $1 \%$ level. Therefore, we find statistical evidence that prior performance affects the behavior in a significant manner.

\subsection{Size}

Table 5 shows the estimated transition matrices for the loading on the size factor. In general, a low factor loading on the SMB factor can be interpreted as a fund focussing on large stocks, and a high factor loading as a fund focussing on small stocks.

The unconditional transition matrix shows a very strong relation between the estimated SMB loading in the first and second half of the year. For example, a fund with a factor loading in Q1 in the first half of the year has a probability of $70.30 \%$ of remaining in Q1 in the second half of the year. For funds focussing on small stocks (Q5) this probability is even higher at $90.55 \%$.

Most elements in the transition matrix for successful funds are significantly different from the unconditional transition matrix. For example, the probability to remain in quintile 1 is $64.15 \%$ compared to $70.30 \%$ in the full sample transition matrix. The mean class for each row is higher for successful funds compared to the unconditional case, e.g., at a value of 1.46 the mean class for the first row is higher than for the full sample at a value of 1.35. This is an indication that successful funds increase the exposure to the size factor.

The transition matrix for unsuccessful funds is very similar to the unconditional matrix, but most elements are not significantly different. A comparison of the mean class after transition reveals that unsuccessful funds lower their exposure to small stocks-except for quintile 1. For example, for the second quintile the mean class is 1.89 compared to 1.97 for the full sample. We conclude that unsuccessful funds try to avoid small stocks.

The last matrix in Table 5 shows the different reaction of successful and unsuccessful funds. The key criterion summarizing the reaction is the difference in the mean class change between top and low-performing funds. For each quintile, these values are positive. This indicates that successful funds increase their exposure to small stocks on average. This reaction is weak in the highest and lowest quintile (Q1 and Q5), but strong in the remaining quintiles. We conclude that successful funds increase their small caps exposure. 
Table 5 Transition probabilities for the loading on the size premium

\begin{tabular}{|c|c|c|c|c|c|c|c|c|c|}
\hline & & \multicolumn{8}{|c|}{ SMB July-December } \\
\hline & & Q1 & Q2 & Q3 & Q4 & Q5 & Mean & $\mathrm{p}$ & $\mathrm{P}$ \\
\hline SMB & Q1 & 70.30 & 24.86 & 4.40 & 0.34 & 0.10 & 1.35 & & \\
\hline \multirow[t]{4}{*}{ January-June } & Q2 & 25.78 & 52.69 & 20.69 & 0.84 & 0.00 & 1.97 & & \\
\hline & Q3 & 3.58 & 22.06 & 60.73 & 13.34 & 0.29 & 2.85 & & \\
\hline & Q4 & 0.25 & 0.37 & 14.10 & 76.22 & 9.06 & 3.93 & & \\
\hline & Q5 & 0.08 & 0.02 & 0.10 & 9.25 & 90.55 & 4.90 & & \\
\hline \multirow{5}{*}{$\begin{array}{l}\text { SMB } \\
\text { top funds }\end{array}$} & Q1 & $64.15^{* *}$ & 26.80 & $8.25^{* *}$ & 0.80 & 0.00 & 1.46 & $0.00 * *$ & \\
\hline & Q2 & $19.59^{* *}$ & $48.42 *$ & $28.84^{* *}$ & $3.16^{* *}$ & 0.00 & 2.16 & $0.00 * *$ & \\
\hline & Q3 & $2.51 *$ & $15.44^{* *}$ & 58.48 & $22.51^{* *}$ & $1.06^{*}$ & 3.04 & $0.00 * *$ & \\
\hline & Q4 & $0.00^{* *}$ & $0.12^{* *}$ & 14.87 & $72.81^{* *}$ & $12.20^{* *}$ & 3.97 & $0.00 * *$ & \\
\hline & Q5 & 0.26 & $0.00^{* *}$ & $0.00^{* *}$ & $6.07^{* *}$ & $93.67^{* *}$ & 4.93 & $0.00^{* *}$ & $0.00^{* *}$ \\
\hline \multirow{5}{*}{$\begin{array}{l}\text { SMB } \\
\text { bottom funds }\end{array}$} & Q1 & 71.20 & $20.94 *$ & 6.02 & 1.05 & $0.79 *$ & 1.39 & $0.00 * *$ & \\
\hline & Q2 & $31.18^{* *}$ & 49.57 & 18.03 & 1.22 & 0.00 & 1.89 & $0.00 * *$ & \\
\hline & Q3 & $8.06^{* *}$ & 23.76 & $56.34 *$ & 11.72 & 0.11 & 2.72 & $0.00 * *$ & \\
\hline & Q4 & $1.04 *$ & 0.80 & $16.24 *$ & 75.48 & $6.45^{* *}$ & 3.86 & $0.00 * *$ & \\
\hline & Q5 & 0.09 & 0.05 & 0.14 & $10.61 *$ & $89.12 *$ & 4.89 & 0.27 & $0.00^{* *}$ \\
\hline \multirow{5}{*}{$\begin{array}{l}\text { Difference } \\
\text { between top } \\
\text { and bottom }\end{array}$} & Q1 & $-7.06^{* *}$ & $5.86^{* *}$ & $2.23 *$ & -0.25 & $-0.79^{* *}$ & 0.06 & 0.07 & \\
\hline & Q2 & $-11.59^{* *}$ & -1.15 & $10.81^{* *}$ & $1.94^{* *}$ & 0.00 & 0.26 & $0.00 * *$ & \\
\hline & Q3 & $-5.56^{* *}$ & $-8.33^{* *}$ & 2.14 & $10.79^{* *}$ & $0.96^{* *}$ & 0.32 & $0.00 * *$ & \\
\hline & Q4 & $-1.04^{* *}$ & $-0.68^{* *}$ & -1.37 & $-2.67 *$ & $5.75^{* *}$ & 0.12 & $0.00 * *$ & \\
\hline & Q5 & 0.17 & $-0.05^{* *}$ & $-0.14^{* *}$ & $-4.54^{* *}$ & $4.56^{* *}$ & 0.04 & $0.00 * *$ & $0.00^{* *}$ \\
\hline
\end{tabular}

The table shows the relation between prior performance and the loading on the size premium based on the four-factor model. The first transition matrix is the unconditional transition matrix. The second transition matrix is the transition matrix for top-performing funds, i.e., funds with an alpha in the highest quantile in the first half of a year. The third transition matrix is the transition matrix for poor-performing funds, i.e., funds with an alpha in the lowest quantile in the first half of year. The last matrix is the difference between the transition matrix of top-performing funds and low-performing funds. The column "Mean" indicates the mean target category for each row of the transition matrix. The column " $p$ " shows the probabilities that the transition probabilities are equal (row-by-row) and the column "P" shows the probabilities that the transition matrices are equal. For top-performing and poor-performing funds, significance ( $t$ test and $\chi^{2}$-test) is tested against the unconditional transition matrix. For the last matrix, zero is used as null hypothesis

* Significance on a $5 \%$ level and $* *$ on a $1 \%$ level

The transition matrices are different from each other in any case as indicated by the $\chi^{2}$-tests. The transition probabilities for single classes are different from each other in 13 out of 15 cases.

\subsection{Value}

In Table 6, we show the estimated transition matrices for the loading on the value factor. A low loading on the value factor can be interpreted as growth investing, and a high loading as value investing. 
Table 6 Transition probabilities for the loading on the value premium

\begin{tabular}{|c|c|c|c|c|c|c|c|c|c|}
\hline & & \multicolumn{8}{|c|}{ HML July-December } \\
\hline & & Q1 & Q2 & Q3 & Q4 & Q5 & Mean & $\mathrm{p}$ & $\mathrm{P}$ \\
\hline HML & Q1 & 64.80 & 25.00 & 7.21 & 2.17 & 0.82 & 1.49 & & \\
\hline \multirow[t]{4}{*}{ January-June } & Q2 & 22.79 & 39.46 & 29.87 & 6.59 & 1.29 & 2.24 & & \\
\hline & Q3 & 8.79 & 25.59 & 33.75 & 24.14 & 7.73 & 2.96 & & \\
\hline & Q4 & 2.40 & 7.09 & 20.47 & 40.86 & 29.16 & 3.87 & & \\
\hline & Q5 & 1.21 & 2.86 & 8.71 & 26.24 & 60.99 & 4.43 & & \\
\hline \multirow{5}{*}{$\begin{array}{l}\text { HML } \\
\text { top funds }\end{array}$} & Q1 & $68.01 *$ & $21.22^{* *}$ & 7.83 & 1.74 & 1.20 & 1.47 & $0.00 * *$ & \\
\hline & Q2 & $28.05^{* *}$ & 36.65 & $25.67 *$ & 7.45 & 2.17 & 2.19 & $0.00 * *$ & \\
\hline & Q3 & 8.36 & 24.23 & $29.74 *$ & 22.54 & $15.13^{* *}$ & 3.12 & $0.00 * *$ & \\
\hline & Q4 & $1.00^{* *}$ & $5.66^{*}$ & $16.22^{* *}$ & $36.27^{* *}$ & $40.85^{* *}$ & 4.10 & $0.00 * *$ & \\
\hline & Q5 & $0.37^{* *}$ & 2.68 & $5.07^{* *}$ & $19.97^{* *}$ & $71.91^{* *}$ & 4.60 & $0.00 * *$ & $0.00^{* *}$ \\
\hline \multirow{5}{*}{$\begin{array}{l}\text { HML } \\
\text { bottom funds }\end{array}$} & Q1 & $59.68^{* *}$ & 25.43 & $11.10^{* *}$ & 2.75 & 1.04 & 1.60 & $0.00 * *$ & \\
\hline & Q2 & $33.05^{* *}$ & $30.36^{* *}$ & $24.51^{* *}$ & $9.47^{* *}$ & $2.60 *$ & 2.18 & $0.00^{* * *}$ & \\
\hline & Q3 & $18.54^{* *}$ & $30.76^{* *}$ & $25.22^{* *}$ & $18.63^{* *}$ & 6.85 & 2.64 & $0.00 * *$ & \\
\hline & Q4 & $7.42^{* *}$ & $13.93^{* *}$ & $28.36^{* *}$ & $29.19^{* *}$ & $21.10^{* *}$ & 3.43 & $0.00 * *$ & \\
\hline & Q5 & $3.65^{* *}$ & $4.93^{* *}$ & $16.27^{* *}$ & $30.25^{* *}$ & $44.90^{* *}$ & 4.08 & $0.00 * *$ & $0.00^{* *}$ \\
\hline \multirow{5}{*}{$\begin{array}{l}\text { HML } \\
\text { between top } \\
\text { and bottom }\end{array}$} & Q1 & $8.33^{* *}$ & $-4.21^{* *}$ & $-3.27^{* *}$ & $-1.01 *$ & 0.16 & -0.13 & 0.06 & \\
\hline & Q2 & $-5.00^{* *}$ & $6.28^{* *}$ & 1.16 & $-2.02 *$ & -0.43 & 0.01 & 0.14 & \\
\hline & Q3 & $-10.18^{* *}$ & $-6.52^{* *}$ & $4.52^{* *}$ & $3.91 *$ & $8.28^{* *}$ & 0.47 & $0.00 * *$ & \\
\hline & Q4 & $-6.42^{* *}$ & $-8.27^{* *}$ & $-12.13^{* *}$ & $7.08^{* *}$ & $19.75^{* *}$ & 0.68 & $0.00 * *$ & \\
\hline & Q5 & $-3.27^{* *}$ & $-2.25^{* *}$ & $-11.21^{* *}$ & $-10.28^{* *}$ & $27.01^{* *}$ & 0.53 & $0.00 * *$ & $0.00^{* *}$ \\
\hline
\end{tabular}

The table shows the relation between prior performance and the loading on the value premium based on the four-factor model. The first transition matrix is the unconditional transition matrix. The second transition matrix is the transition matrix for top-performing funds, i.e., funds with an alpha in the highest quantile in the first half of a year. The third transition matrix is the transition matrix for poor-performing funds, i.e., funds with an alpha in the lowest quantile in the first half of year. The last matrix is the difference between the transition matrix of top-performing funds and low-performing funds. The column "Mean" indicates the mean target category for each row of the transition matrix. The column " $p$ " shows the probabilities that the transition probabilities are equal (row-by-row) and the column "P" shows the probabilities that the transition matrices are equal. For top-performing and poor-performing funds, significance ( $t$ test and $\chi^{2}$-test) is tested against the unconditional transition matrix. For the last matrix, zero is used as null hypothesis

* Significance on a $5 \%$ level and $* *$ on a $1 \%$ level

The unconditional transition matrix shows a high persistence in the choice of the risk level to value stocks. For example, the probabilities to remain in the same quintile is $64.80 \%$ for the first quintile and $60.99 \%$ for the fifth quintile. The degree of persistence is therefore lower than for the size exposure, but higher than for the market risk exposure.

Most elements of the transition matrix for successful funds are significantly different from the unconditional matrix. We observe a different reaction among different groups. For quintile 1 and 2, we observe a small reduction in the risk exposure if we use the mean class after transition as the relevant criterion. Successful growth stocks increase 
their exposure to growth stocks. However, for funds following a value strategy (Q3 to Q5), the reaction is different. After a period of good performance, these funds increase their exposure to value stocks. Summarizing, we find an asymmetric reaction for value and growth funds.

For unsuccessful funds, we find a similarly asymmetric reaction for value and growth funds in a different direction. Unsuccessful growth funds focus, on average, more on a value strategy. Unsuccessful value funds focus more on a growth strategy. For example, the mean class after transition for quintile 5 is 4.08 for poor-performing funds, 4.43 for all funds, and 4.60 for top-performing funds.

These combined effects lead to strong differences in the behavior of these two groups of mutual funds. Positive past performance induces, in general, an increased exposure to the value premium-except for funds in Q1.

The $\chi^{2}$-tests indicate that all transition matrices are statistically different. Similarly, the transition probabilities are different from each other in 13 out of 15 cases. Overall, we find statistical evidence for a change in the behavior of mutual fund managers.

\subsection{Momentum}

Table 7 shows the transition matrices for the loading on the momentum factor. A low factor loading is interpreted as a fund that avoids momentum stocks in asset allocation. Consequently, a high factor loading can be interpreted as a fund that invests heavily in momentum stocks.

The transition matrix shows some degree of persistence in the choice of the risk level. For example, the probabilities of remaining in the same quintile is $52.21 \%$ for Q5 and $45.67 \%$ for Q1. The magnitude of the persistence in the choice of the risk level is roughly comparable to the market risk where mutual fund manager also change the exposure frequently. The degree of persistence is lower than for the size and value exposure.

For successful funds, we find a clear pattern of increasing the exposure to the momentum factor. For example, the mean class after transition is 2.33 for quintile 1 compared to 2.21 for the full sample and 4.08 compared to 4.02 for quintile 5 .

Unsuccessful funds show a similar, but reversed pattern in their reaction to past performance. Poor-performing funds decrease their exposure to the momentum factor on average. For example, the mean class after transition for quintile 1 is 2.18 compared to 2.21 and for quintile 53.99 compared to 4.02 .

The last matrix in Table 7 shows the combined effects of the changed risk exposure. The strongly positive difference of the mean classes after transition shows that successful funds have a higher tendency to increase the exposure to momentum stocks. For example, for quintile 3 the mean class difference is 0.73 . This indicates that successful funds are much more likely to take more momentum risk. The effect differs for different quintiles and is weaker for the first and fifth quintile.

From a statistical perspective, the $\chi^{2}$-tests show that most findings are significant. The transition matrices are not equal to each other and the row-by-row transition probabilities in all except two cases also different from each other. 
Table 7 Transition probabilities for the loading on the momentum premium

\begin{tabular}{|c|c|c|c|c|c|c|c|c|c|}
\hline & & \multicolumn{8}{|c|}{ UMD July-December } \\
\hline & & Q1 & Q2 & Q3 & Q4 & Q5 & Mean & $\mathrm{p}$ & $\mathrm{P}$ \\
\hline UMD & Q1 & 45.67 & 20.51 & 11.88 & 10.64 & 11.30 & 2.21 & & \\
\hline \multirow[t]{4}{*}{ January-June } & Q2 & 19.97 & 34.35 & 23.21 & 15.24 & 7.23 & 2.55 & & \\
\hline & Q3 & 15.14 & 24.65 & 33.44 & 19.64 & 7.12 & 2.79 & & \\
\hline & Q4 & 10.79 & 13.60 & 20.35 & 33.13 & 22.13 & 3.42 & & \\
\hline & Q5 & 8.42 & 6.91 & 11.13 & 21.33 & 52.21 & 4.02 & & \\
\hline UMD & Q1 & 44.26 & $17.56^{*}$ & 12.70 & 11.89 & $13.59^{*}$ & 2.33 & $0.01 * *$ & \\
\hline \multirow[t]{4}{*}{ top funds } & Q2 & $16.74 *$ & $26.49^{* *}$ & 25.05 & $20.23^{* *}$ & $11.50^{* *}$ & 2.83 & $0.00 * *$ & \\
\hline & Q3 & $10.77^{* *}$ & $12.63^{* *}$ & 34.87 & $29.87^{* *}$ & $11.85^{* *}$ & 3.19 & $0.00 * *$ & \\
\hline & Q4 & $7.40^{* *}$ & $10.15^{* *}$ & $17.15^{* *}$ & $36.59 *$ & $28.72^{* *}$ & 3.69 & $0.00 * *$ & \\
\hline & Q5 & 7.74 & 5.81 & 10.92 & 22.05 & 53.49 & 4.08 & 0.38 & $0.00^{* *}$ \\
\hline UMD & Q1 & $50.62^{* *}$ & 18.86 & $6.16^{* *}$ & 10.28 & $14.08^{* *}$ & 2.18 & $0.00 * *$ & \\
\hline \multirow[t]{4}{*}{ bottom funds } & Q2 & $29.30^{* *}$ & $26.71^{* *}$ & $18.02^{* *}$ & 17.10 & 8.87 & 2.50 & $0.00 * *$ & \\
\hline & Q3 & $30.83^{* *}$ & 26.35 & $16.98^{* *}$ & $16.88^{*}$ & 8.96 & 2.47 & $0.00 * *$ & \\
\hline & Q4 & $17.62^{* *}$ & 14.45 & 20.80 & $26.54^{* *}$ & 20.59 & 3.18 & $0.00 * *$ & \\
\hline & Q5 & 8.12 & $8.83^{*}$ & 11.75 & $19.02 *$ & 52.28 & 3.99 & $0.02 *$ & $0.00^{* *}$ \\
\hline \multirow{5}{*}{$\begin{array}{l}\text { Difference } \\
\text { between top } \\
\text { and bottom }\end{array}$} & Q1 & $-6.37^{* *}$ & -1.30 & $6.55^{* *}$ & 1.61 & -0.49 & 0.15 & $0.00 * *$ & \\
\hline & Q2 & $-12.56^{* *}$ & -0.22 & $7.03^{* *}$ & $3.13^{*}$ & $2.63^{*}$ & 0.34 & $0.00 * *$ & \\
\hline & Q3 & $-20.06^{* *}$ & $-13.72^{* *}$ & $17.89^{* *}$ & $13.00^{* *}$ & $2.89^{*}$ & 0.73 & $0.00 * *$ & \\
\hline & Q4 & $-10.23^{* *}$ & $-4.30^{* *}$ & $-3.65^{* *}$ & $10.05^{* *}$ & $8.12^{* *}$ & 0.51 & $0.00 * *$ & \\
\hline & Q5 & -0.38 & $-3.03^{* *}$ & -0.83 & $3.03^{*}$ & 1.21 & 0.09 & 0.17 & $0.00^{* *}$ \\
\hline
\end{tabular}

The table shows the relation between prior performance and the loading on the momentum premium based on the four-factor model. The first transition matrix is the unconditional transition matrix. The second transition matrix is the transition matrix for top-performing funds, i.e., funds with an alpha in the highest quantile in the first half of a year. The third transition matrix is the transition matrix for poor-performing funds, i.e., funds with an alpha in the lowest quantile in the first half of year. The last matrix is the difference between the transition matrix of top-performing funds and low-performing funds. The column "Mean" indicates the mean target category for each row of the transition matrix. The column "p" shows the probabilities that the transition probabilities are equal (row-by-row) and the column "P" shows the probabilities that the transition matrices are equal. For top-performing and poor-performing funds, significance ( $t$ test and $\chi^{2}$-test) is tested against the unconditional transition matrix. For the last matrix, zero is used as null hypothesis

* Significance on a $5 \%$ level and ${ }^{* *}$ on a $1 \%$ level

\subsection{Tracking error}

In Table 8, we show the estimated transition probabilities for the tracking error. The tracking error measures the deviation from the benchmark and can therefore be used as a proxy for active portfolio management. Low values correspond to a passive investment style, high values to an active investment style.

For the unconditional transition matrix, we find a very high degree of persistence in the section of the tracking error. For example, the probability to remain in quintile 1 is $81.17 \mathrm{v} .76 .40 \%$ tom remain in quintile 5 . This high degree of persistence is comparable to the pattern we observed for the loading on the size factor. 
Table 8 Transition probabilities for the tracking error

\begin{tabular}{|c|c|c|c|c|c|c|c|c|c|}
\hline & & \multicolumn{8}{|c|}{ Tracking error July-December } \\
\hline & & Q1 & Q2 & Q3 & Q4 & Q5 & Mean & $\mathrm{p}$ & $\mathrm{P}$ \\
\hline Tracking error & Q1 & 81.17 & 16.31 & 1.65 & 0.37 & 0.50 & 1.23 & & \\
\hline \multirow[t]{4}{*}{ January-June } & Q2 & 15.98 & 58.45 & 21.70 & 3.08 & 0.79 & 2.14 & & \\
\hline & Q3 & 1.56 & 21.29 & 51.92 & 22.89 & 2.34 & 3.03 & & \\
\hline & Q4 & 0.49 & 3.33 & 22.44 & 53.78 & 19.97 & 3.89 & & \\
\hline & Q5 & 0.79 & 0.62 & 2.30 & 19.89 & 76.40 & 4.70 & & \\
\hline \multirow{5}{*}{$\begin{array}{l}\text { Tracking error } \\
\text { top funds }\end{array}$} & Q1 & 78.86 & 18.29 & 2.18 & 0.00 & 0.67 & 1.25 & 0.25 & \\
\hline & Q2 & $13.66^{*}$ & 58.93 & 22.38 & 4.21 & 0.82 & 2.20 & 0.11 & \\
\hline & Q3 & $0.85^{*}$ & 20.60 & 52.39 & 23.07 & 3.09 & 3.07 & 0.10 & \\
\hline & Q4 & 0.72 & 3.49 & $20.09 *$ & 53.03 & $22.66^{*}$ & 3.93 & $0.02 *$ & \\
\hline & Q5 & $1.66^{*}$ & 0.58 & 2.43 & 20.00 & 75.34 & 4.67 & $0.00 * *$ & $0.00^{* *}$ \\
\hline \multirow{5}{*}{$\begin{array}{l}\text { Tracking Error } \\
\text { bottom funds }\end{array}$} & Q1 & $75.76 *$ & 19.76 & 2.04 & $2.04 *$ & 0.41 & 1.32 & $0.00 * *$ & \\
\hline & Q2 & $12.50 *$ & 56.85 & $25.54 *$ & 3.76 & 1.34 & 2.25 & $0.00 * *$ & \\
\hline & Q3 & 1.54 & $14.38^{* *}$ & 53.67 & $27.03^{* *}$ & 3.38 & 3.16 & $0.00 * *$ & \\
\hline & Q4 & $0.07^{* *}$ & $1.77^{* *}$ & $19.32^{* *}$ & $59.04^{* *}$ & 19.80 & 3.97 & $0.00 * *$ & \\
\hline & Q5 & $0.18^{* *}$ & 0.50 & 2.21 & $17.76^{*}$ & $79.35^{* *}$ & 4.76 & $0.00 * *$ & $0.00^{* *}$ \\
\hline \multirow{5}{*}{$\begin{array}{l}\text { Difference } \\
\text { between top } \\
\text { and bottom }\end{array}$} & Q1 & 3.10 & -1.47 & 0.14 & $-2.04^{* *}$ & 0.26 & -0.06 & 0.20 & \\
\hline & Q2 & 1.16 & 2.08 & $-3.16^{*}$ & 0.45 & -0.52 & -0.05 & 0.80 & \\
\hline & Q3 & $-0.70 *$ & $6.22^{* *}$ & -1.28 & $-3.96^{* *}$ & -0.29 & -0.09 & 0.08 & \\
\hline & Q4 & $0.66^{* *}$ & $1.72^{* *}$ & 0.77 & $-6.01^{* *}$ & $2.87 *$ & -0.03 & $0.02 *$ & \\
\hline & Q5 & $1.48^{* *}$ & 0.08 & 0.21 & $2.24 *$ & $-4.01^{* *}$ & -0.09 & $0.00 * *$ & $0.00^{* *}$ \\
\hline
\end{tabular}

The table shows the relation between prior performance and the tracking error based on the four-factor model. The first transition matrix is the unconditional transition matrix. The second transition matrix is the transition matrix for top-performing funds, i.e., funds with an alpha in the highest quantile in the first half of a year. The third transition matrix is the transition matrix for poor-performing funds, i.e., funds with an alpha in the lowest quantile in the first half of year. The last matrix is the difference between the transition matrix of top-performing funds and low-performing funds. The column "Mean" indicates the mean target category for each row of the transition matrix. The column "p" shows the probabilities that the transition probabilities are equal (row-by-row) and the column "P" shows the probabilities that the transition matrices are equal. For top-performing and poor-performing funds, significance ( $t$ test and $\chi^{2}$-test) is tested against the unconditional transition matrix. For the last matrix, zero is used as null hypothesis

* Significance on a $5 \%$ level and $* *$ on a $1 \%$ level

Most probabilities in the transition matrix are not significantly different from the unconditional probabilities, but we find a tendency to increase the tracking error for some quintiles. For quintiles $1-4$, the mean class after transition is slightly higher than for the unconditional case, e.g., for the first quintile the mean class is 1.25 compared to 1.23 for the unconditional case. For quintile 5, we find small evidence that these funds decrease their tracking error with a mean class of 4.67 compared to 4.70 for the unconditional case.

We find that unsuccessful funds show in most cases a significant change in behavior compared to the full sample case. Poor-performing funds increase the tracking error 
for all quintiles. The mean class after transition is always higher than for the sample average. For example, for the first quintile, the mean class is 1.32 compared to 1.23 for the full sample.

A comparison of the transition matrix for successful and unsuccessful funds shows that poor-performing funds decrease the tracking error. The magnitude is small with a mean difference in the class after transition of -0.03 to -0.09 .

The statistical evidence is in the case of the tracking error a little lit weaker than for other variables. Based on the $\chi^{2}$-tests, all transition matrices are different from each other. For the single-class transition probabilities 7 out of 15 are not equal to each other.

\subsection{Subsamples}

Table 9 shows the transition matrices for various subsamples. We split the full sample into various subsamples using market capitalization (large caps, medium caps, small caps) and investment style (blended, growth, value) as criteria. The table shows the difference of the transition matrices for top and poor-performing funds for volatility. Therefore, Table 9 is similar to the fourth transition matrix in Table 3. Positive probabilities mean that top-performing funds are more likely to choose a higher volatility.

The analysis of the subsamples shows that previous findings are very robust. In the full-sample analysis we find that successful fund managers increase the volatility of their fund. The mean difference class after transition is positive in almost all subsamples. This indicates that top-performing funds increase the volatility to a stronger extent than poor-performing funds. However, the magnitude of this adjustment is different for various subsamples. For example, for large cap funds the mean classes are between 0.09 and 0.03 , for value funds between 0.13 and 1.18 . In general, we observe that for capitalization-sorted funds, the change in behavior in smaller than for style-sorted funds.

The $\chi^{2}$-tests show that all transition matrices are different from each offer on a $1 \%$ level. Therefore, we find statistical evidence that prior performance affects the behavior in a significant manner.

\subsection{Discussion}

In this section, we discuss the results of our econometric analysis with respect to theoretical models and with respect to other empirical findings.

Existing literature trying to explain the behavior of mutual fund managers (e.g., Brown et al. 1996; Chevalier and Ellison 1997; Carpenter 2000; Busse 2001, and Carhart et al. 2002) has focussed on incentives faced by mutual fund managers. Incentives in the mutual fund industry are primarily driven by the behavior of investors. Investors allocate a large proportion of new capital to funds with a high performance in the previous period whereas they do not withdraw invested capital from poorly performing funds. Therefore, investors' behavior induces a convex relation between fund performance and fund size. This may lead to excessive risk taking by mutual fund managers, if a manager's salary depends on the assets under management. 
Table 9 Transition probabilities for volatility for subsamples

\begin{tabular}{|c|c|c|c|c|c|c|c|c|c|}
\hline & & \multicolumn{8}{|c|}{ Volatility July-December } \\
\hline & & Q1 & Q2 & Q3 & Q4 & Q5 & Mean & $\mathrm{p}$ & $\mathrm{P}$ \\
\hline \multirow[t]{5}{*}{ Large cap } & Q1 & $-9.08^{* *}$ & $8.01^{* *}$ & 0.55 & -0.51 & 1.02 & 0.12 & 0.26 & \\
\hline & Q2 & $-18.34^{* *}$ & $6.53 *$ & $12.95^{* *}$ & -1.69 & 0.55 & 0.30 & $0.00 * *$ & \\
\hline & Q3 & $-2.69 *$ & $-5.38 *$ & 2.68 & $5.35^{*}$ & 0.03 & 0.16 & 0.39 & \\
\hline & Q4 & 0.59 & $-3.62 *$ & -2.63 & -1.39 & $7.05^{* *}$ & 0.15 & 0.22 & \\
\hline & Q5 & $-0.88^{* *}$ & -0.43 & 1.24 & $-7.00^{* *}$ & $7.07^{* *}$ & 0.09 & $0.03 *$ & $0.00^{* *}$ \\
\hline \multirow[t]{5}{*}{ Medium cap } & Q1 & $-8.71^{* *}$ & 0.31 & $6.20^{* *}$ & $2.41 *$ & -0.21 & 0.19 & 0.62 & \\
\hline & Q2 & -4.73 & $9.89 *$ & -2.33 & -2.05 & -0.79 & -0.04 & 0.78 & \\
\hline & Q3 & $-13.42^{* *}$ & 2.68 & -0.70 & 6.27 & $5.18^{*}$ & 0.41 & $0.05^{*}$ & \\
\hline & Q4 & $-5.71^{* *}$ & 0.52 & 5.77 & $-16.52^{* *}$ & $15.94^{* *}$ & 0.26 & $0.02 *$ & \\
\hline & Q5 & $-5.96^{* *}$ & $-1.60 * *$ & 2.97 & $7.44 *$ & -2.85 & 0.15 & $0.01 * *$ & $0.00^{* *}$ \\
\hline \multirow[t]{5}{*}{ Small cap } & Q1 & $-5.13 *$ & 1.50 & $3.72 *$ & -0.50 & 0.41 & 0.09 & 0.95 & \\
\hline & Q2 & $-19.87^{* *}$ & $16.99^{* *}$ & -2.10 & $7.13^{* *}$ & $-2.15^{*}$ & 0.26 & $0.03 *$ & \\
\hline & Q3 & $-3.99 * *$ & 0.70 & $6.92 *$ & -3.63 & 0.01 & 0.04 & 0.57 & \\
\hline & Q4 & -1.31 & $-8.19^{* *}$ & 0.57 & $10.92 *$ & -1.99 & 0.18 & 0.19 & \\
\hline & Q5 & -0.19 & $5.11 *$ & -0.44 & -0.75 & -3.73 & -0.13 & $0.04 *$ & $0.00^{* *}$ \\
\hline \multirow[t]{5}{*}{ Blended } & Q1 & $-15.16^{* *}$ & 0.31 & $3.15^{*}$ & $3.98^{* *}$ & $7.73^{* *}$ & 0.49 & $0.00 * *$ & \\
\hline & $\mathrm{Q} 2$ & $-22.95^{* *}$ & -3.26 & 2.07 & -2.85 & $26.99^{* *}$ & 1.00 & $0.00 * *$ & \\
\hline & Q3 & $-15.99^{* *}$ & $-16.37^{* *}$ & $13.36^{* *}$ & $8.88^{* *}$ & $10.12^{* *}$ & 0.77 & $0.00 * *$ & \\
\hline & $\mathrm{Q} 4$ & $-1.94^{* *}$ & $-4.60^{* *}$ & $-16.92^{* *}$ & $8.97^{* *}$ & $14.49^{* *}$ & 0.46 & $0.00 * *$ & \\
\hline & Q5 & -0.89 & $-2.01 *$ & $-2.43^{* *}$ & $-6.62^{* *}$ & $11.95^{* *}$ & 0.21 & $0.02 *$ & $0.00^{* *}$ \\
\hline \multirow[t]{5}{*}{ Growth } & Q1 & $-16.92^{* *}$ & $7.26^{* *}$ & $6.11^{* *}$ & $2.77 *$ & 0.78 & 0.31 & $0.00 * *$ & \\
\hline & $\mathrm{Q} 2$ & $-19.20^{* *}$ & $-7.96^{* *}$ & $11.28^{* *}$ & $6.10^{* *}$ & $9.78^{* *}$ & 0.72 & $0.00 * *$ & \\
\hline & Q3 & $-20.53^{* *}$ & $-9.54^{* *}$ & $6.24 *$ & $18.54^{* *}$ & $5.29^{* *}$ & 0.80 & $0.00 * *$ & \\
\hline & Q4 & $-5.48^{* *}$ & $-14.80^{* *}$ & $-5.18^{* *}$ & $23.34^{* *}$ & 2.12 & 0.53 & $0.00 * *$ & \\
\hline & Q5 & $-1.73^{* *}$ & $-1.73^{* *}$ & $-3.72^{* *}$ & $8.69^{* *}$ & -1.52 & 0.11 & $0.00^{* *} *$ & $0.00^{* *}$ \\
\hline \multirow[t]{5}{*}{ Value } & Q1 & $-20.94^{* *}$ & $8.59^{* *}$ & -2.15 & $7.95^{* *}$ & $6.55^{* *}$ & 0.54 & $0.00 * *$ & \\
\hline & Q2 & $-25.68^{* *}$ & $-15.45^{* *}$ & $15.85^{* *}$ & -0.45 & $25.74^{* *}$ & 1.18 & $0.00 * *$ & \\
\hline & Q3 & $-15.80^{* *}$ & $-21.60^{* *}$ & $9.97^{* *}$ & $8.09^{* *}$ & $19.34^{* *}$ & 1.00 & $0.00 * *$ & \\
\hline & Q4 & $-5.89^{* *}$ & $-16.35^{* *}$ & $-10.27^{* *}$ & $21.40^{* *}$ & $11.11^{* *}$ & 0.72 & $0.00 * *$ & \\
\hline & Q5 & 0.79 & $-2.41^{* *}$ & $-4.85^{* *}$ & 0.74 & $5.72 *$ & 0.13 & 0.06 & $0.00^{* *}$ \\
\hline
\end{tabular}

The table shows the relation between prior performance and volatility based on the mean-variance model for various subsamples. For each subsample, we show the difference between the transition matrix of topperforming funds and low-performing funds. Zero is used as null hypothesis

* Significance on a $5 \%$ level and $* *$ on a $1 \%$ level

In our empirical analysis, however, we are unable to find evidence for such a behavior. In general, our findings can be explained by the different setting of this study compared to other empirical studies. In particular, we use a larger sample of funds and different measures of risk and return. Moreover, we impose less restrictive assumptions for the empirical analysis, e.g., we do not assume any linear relation or normal 
distribution. In particular, Brown et al. (1996) solely focus on volatility as a measure of risk and only use a rather small sample of funds, namely funds focussing on growth stocks, over a time period of 15 years. Their analysis focusses on mid-year effects and they find that funds performing poorly by mid-year increase their volatility for the rest of the year. Busse (2001) uses a very similar methodology and the same data set as in Brown et al. (1996), but with a daily frequency. He finds that the fund's intrayear change is attributable to changes in the volatility of common stocks and is not related to changing factor exposures or residual risk. Similarly, Chevalier and Ellison (1997) analyze the impact of past performance on fund flows using a semi-parametric approach. Their results confirm prior expectations, i.e., the flow-performance relation creates incentives for fund managers to adjust the riskiness of the fund depending on mid-year performance.

Ammann and Verhofen (2007) find comparable patterns as in this study. While this study focuses on effects within a year, Ammann and Verhofen (2007) focus on strategy changes over different years. They find that prior performance has a positive impact on the choice of the risk level, i.e., successful fund managers take more risk in the following calendar year.

How can we explain increased risk taking after a period of good performance and decreased risk taking after a period of poor performance? Our explanation is two-sided. First, poor-performing managers might follow a strategy to minimize the risk of their own future replacement when relative performance and not absolute performance is relevant. Second, successful managers might take more risk as they become more confident in their own skills. Success creates confidence. Basically, our analysis shows that a combination of the models by Lynch and Musto (2003) for unsuccessful managers and Berk and Green (2004) for successful managers describes the data best.

Lynch and Musto (2003) propose a model in which strategy changes only occur after periods of bad performance. However, a priori, their model does not say how the strategy changes. In their empirical analysis, they find evidence for a change of factor loadings. They find that poor performers seem to increase their UMD loading and decrease their HML loading. Neither market beta nor SMB loading is systematically affected by fund performance. The different results by Lynch and Musto (2003) in comparison to our analysis might be due to the shorter sample period in the analysis by Lynch and Musto (2003) and to the non-linear model in our analysis. Our analysis shows that, after a period of bad performance, funds take less market risk, decrease their exposure to value, and increase their exposure to large caps and stocks with a low momentum effect.

Berk and Green (2004) propose a model that incorporates two important features. First, performance is not persistent, i.e., active portfolio managers do not outperform passive benchmarks on average. Second, fund flows rationally respond to past performance. In particular, they assume that investors behave as Bayesians, i.e., they update their beliefs about a fund manager's skill based on observed returns and prior beliefs. The same argument can be applied to a manager's belief about his own skills. Starting with some prior confidence on his own skills, he learns about his skills and uses his skills in the following time period. If skills require specific trading strategies, e.g., if 
a fund manager has special skills in selecting small caps or value stocks, an empirical analysis will show patterns as we have observed.

But are investors hurt by the change in the risk-exposure? As shown by a number of authors (e.g., Fama and French 1993; Carhart 1997), the value premium (HML), the size premium (SMB), and the momentum premium (UMD) are priced risk factors. An investor who increases his exposure to these risk factors can expect to earn a return in excess of the risk-free rate. A mutual fund manager who increases the exposure for these stocks creates, in general, an additional return for his fund. Mutual fund investors can profit from this behavior. Therefore, investors holding successful funds benefit from the increased exposure to the size factor, the value factor, the momentum factor, and the market risk factor. Investors holding unsuccessful funds suffer from a decreased exposure to the four risk factors.

\section{Conclusion}

How do mutual fund managers react to past performance? Theory suggests that goodperforming mutual fund managers reduce their risk level and poor-performing managers take more risk because they do not bear the downside risk. However, such a behavior might be unrealistic in actual life due to restrictions fund managers face, such as tracking error restrictions. Moreover, other factors affecting the behavior of mutual fund managers might be more important than pure compensation maximization.

In this paper, we analyze a large sample of US investments funds for a period of 5 years. For each year, we compute different measures of style and risk. In contrast to existing studies, we do not solely focus on volatility as a measure of risk, but also take into account other measures such as the beta and the tracking error, as well as style measures such as the high-minus-low (HML) factor, the small-minus-big (SMB) factor, and the momentum (UMD) factor. Furthermore, we use a robust, non-parametric approach. We are able to capture a wide range of non-linear and asymmetric patterns because we do not impose any restrictive distributional assumptions. Concerning the data base, we do not use only a sub-group of mutual funds, but the complete set of all US equity funds.

Our analysis does not lend support to the hypothesis that poor-performing fund managers increase the risk level. We find that good prior performance in the first half of the year has, in general, a positive impact on the choice of the risk level in the second half of the year. Successful fund managers increase the volatility, the beta, and assign a higher proportion of their portfolio to value stocks, small firms, and momentum stocks in comparison to unsuccessful fund managers. Unsuccessful fund manager increase, on average, only the tracking error.

\section{References}

Ammann, M., Verhofen, M.: Prior performance and risk-taking of mutual fund managers: a dynamic bayesian network approach. J Behav Financ 8, 20-34 (2007)

Berk, J., Green, R.: Mutual fund flows and performance in rational markets. J Polit Econ 112, 1269-1295 (2004)

Brown, K., Harlow, W., Starks, L.: Of tournaments and temptations: an analysis of managerial incentives in the mutual fund industry. J Financ 51, 85-110 (1996) 
Busse, J.: Another look at mutual fund tournaments. J Financ Quant Anal 36, 53-73 (2001)

Carhart, M.: On persistence in mutual fund performance. J Financ 52, 57-82 (1997)

Carhart, M.M., Kaniel, R., Musto, D.K., Reed, A.V.: Learning for the tape: evidence of gaming behavior in equity mutual funds. J Financ 68, 661-693 (2002)

Carpenter, J.: Does option compensation increase managerial risk appetite?. J Financ 55, 2311-2331 (2000)

Chevalier, J., Ellison, G.: Risk taking by mutual funds as a response to incentives. J Polit Econ 105, 1167-1200 (1997)

Daniel, K., Grinblatt, M., Titman, S., Wermers, R.: Measuing mutual fund performance with characteristicbased benchmarks. J Financ 52, 1035-1058 (1997)

Deli, D.N.: Mutual fund advisory contracts: an empirical investigation. J Financ 57, 109-133 (2002)

Fama, E., French, K.: The cross-section of expected stock returns. J Financ 47, 427-465 (1992)

Fama, E., French, K.: Common risk factors in the returns on stocks and bonds. J Financ Econ 33, 3-57 (1993)

Höse, S., Huschens, S., Wania, R.: Rating migrations. In: Härdle, W., Kleinow, T., Stahl, G. (eds.) Applied Quantitative Finance, Chapter 4, pp. 87-110. New York: Springer (2002)

Kothari, S., Warner, J.B.: Evaluating mutual fund performance. J Financ 56, 1985-2010 (2001)

Lynch, A., Musto, D.: How investors interpret past fund returns. J Financ 58, 2033-2058 (2003)

Wermers, R.: Mututal fund performance: an empirical decomposition into stock-picking, style, transactions costs, and expenses. J Financ 55, 1655-1695 (2000) 